\title{
FROM THE UPLANDS OF MINDANAO Healing a Fragmented Land and Its People Through an Integral Ecological Approach
}

\author{
J. ANDRES F. IGNACIO \\ Institute of Environmental Science for Social Change (ESSC) \\ Ateneo de Manila University, Quezon City, Philippines \\ andresignacio@essc.org.ph
}

\begin{abstract}
Upland degradation has been a growing concern in the Philippines in the wake of extensive logging and clearing in the 1970s-1980s. As forests vital to the water supplies of burgeoning communities were depleted, the chances of these areas regenerating were set back by the encroachment of intensive agriculture that extended into the uplands. Genetically modified (GM) corn heavily marketed from the early 2000s onward now dominates the marginal uplands of Northern and Central Mindanao through burning in the dry season, adjacent to remaining forest stands and grasslands. Together with the abuse of the soil in pursuit of economic growth, a parallel exploitation of smallholder corn farmers has fueled this degradation, one that has increasingly pushed upland communities into poverty and debt through the unscrupulous financing of private individuals. This paper thus seeks to bring to the fore, among national and local stakeholders, the gravity and urgency of the socioeconomic, social justice, and land use change crises looming in the uplands of this part of Mindanao. An emphasis on alternative and appropriate forms of livelihood for upland communities is being developed to address land degradation in the form of capacity building in forest and water management, eco-agriculture, and bamboo production, processing, and building, to name a few. Most important, however, is the security of indigenous communities' land rights, better government agroforestry services, and greater transparency in water access, use, and related services. All of these integrated efforts, coupled with a holistic leadership formation targeted at the youth, aim to broaden perspectives that emphasize integral ecology and community.
\end{abstract}

\section{KEYWORDS}

upland degradation; GM corn; smallholder corn farming; culture-based education; culturally-sensitive leadership formation; integral ecology 
In 2007, the ratio of urban to rural population distribution on a global scale was almost equal; in 2017, the World Bank placed the urban population at 55\% (World Bank, 2018). This reveals a steady increase in urban dwellers as caused by a number of factors, one of which is rural to urban migration fueled by the lack of economic opportunities in the countryside.

Of the three billion people living in rural areas in the developing world, about two-thirds live in 475 million small farm households and work on land plots smaller than two hectares (Lowder, Skoet, \& Singh, 2014: 45). Poor, food insecure, and with restricted access to markets and services, many of these smallholder farmers are engaged in other informal economic activities to augment their meager incomes (Rapsomanikis, 2015). Farming can also be very risky in developing countries which are vulnerable to impacts from natural disasters or anthropogenic crises and where efforts to cushion families from these perturbations and enable them to survive through lean times are limited (Harvey, 2018). Furthermore, local opportunities for the rural youth in developing economies face a major challenge due to increasingly limited prospects and security, particularly in the marginal countryside areas (FAO, 2018).

According to the 2012 Census of Agriculture and Fisheries ${ }^{1}$ conducted by the Philippine Statistics Authority (PSA, 2015: 20), for instance, 89\% $(4,945,298)$ of all agricultural landholdings in the Philippines $(5,562,577)$ are less than three hectares in size, with $64 \%(3,164,596)$ of these measuring less than one. This reveals a rather large percentage of smallholder farmers who have limited land to till.

This is in stark contrast with the Philippine uplands (areas having a slope gradient above 18\%), which are normally classified as forest lands and under the legal jurisdiction of the Department of Environment and Natural Resources (DENR) under the Forestry Reform Code of the Philippines (President of the Philippines, 1975). Around 49\% (approx. 14.7 million hectares) of the country's total area of 30 million hectares $^{2}$ are classified as uplands (Espiritu, Casin, \& Camacho, 2010), with roughly $42 \%$ of this total upland area still containing forest based on satellite imagery as of 2002, making for roughly 8.5 million hectares of denuded uplands throughout the country (Walpole, 2010). 
The uplands, particularly in the islands of Luzon and Mindanao, are home to many of the Indigenous Peoples (IPs) of the Philippines whose ancestral domains were logged in the 1960s and 70s. They have since moved to higher lands in many areas to avoid conflict and the influx of migrant farmers, and now live next to the last remaining forests of the Philippines. Areas cleared of the original forest cover have been burned and are now dominated by imperata cylindrica (cogon) grass with a marginal agriculture of corn and root crops along with the small gardens of the migrants.

Corn as a food staple in Bukidnon Province in Mindanao, for example, has been the basic extensive agriculture. With the availability of fertilizers and pesticides in recent years, farms have become much more intensive areas for corn which now supplies the animal feed industry. It is the second major agricultural crop of the Philippines and has exhibited a steady increase in production since 2003 (PSA, 2009). A total of 7.377 million metric tons were produced in 2013 (PSA, 2014), corresponding to a total planted area of 2.29 million hectares assuming an average yield of 3.21 metric tons/hectare (Padilla, 2011).

The increasing trend of corn production in the Philippines in general shows that there is indeed economic viability in corn, particularly when it comes to fulfilling the growing demand for animal feed which accounts for $60 \%$ of its total production yield (Padilla, 2011). Yet while corn cultivation is an agricultural activity promoted by the Department of Agriculture, much of the areas cultivated for this crop are in denuded upland areas under the legal jurisdiction of the DENR. Indeed, most corn is planted in upland plains and rolling to hilly fields (Gerpacio, Labios, Labios, \& Diangkinay, 2004) which are generally referred to as upland areas.

\section{THE PLIGHT OF SMALLHOLDER CORN FARMERS IN THE PHILIPPINES}

The Philippines has struggled hard over the last three decades to regain a level of political integrity after almost twenty years of dictatorial rule under ousted former president Ferdinand Marcos. During that time, the suppression of freedom of speech, corruption, and oppression were the norms that stunted growth especially for the poor and marginalized majority of the population. Yet while the transition has not been altogether easy, the country as a whole has been slowly and finally recognized globally for its soaring economic growth (Robinson, 2015). More recent leadership 
changes, however, have jeopardized these recent gains once again with the apparent return of human rights abuses characteristic of the Marcos dictatorship of old.

Yet despite the favorable and generally improving economic climate, poverty has been a rising concern throughout the country, with a very high relative proportion of the poor belonging to the agriculture sector (Reyes, Tabuga, Asis, \& Datu, 2012). This partly explains why a majority of Philippine farms are engaged in smallholder agriculture. In terms of trends in Philippine agriculture, markets and not production are increasingly what drive development in the sector which is rapidly being defined in the international arena (Cardenas, 2008).

The incidence of poverty among agricultural households in 2009 was 57\%, thrice (17\%) that of non-agricultural households (Reyes et al., 2012). In the same report, Reyes notes that households with heads that are engaged primarily in corn growing have the highest comparative poverty incidence at $64 \%$ compared to households of other crop growers. Being food poor (or subsistence poor) is also highest in the corn sector at $37 \%$. It thus follows that households that rely on corn as their main source of livelihood have the greatest deprivation from basic amenities such as potable water and electricity. These figures essentially show that farmers engaged in corn production are the poorest in the agriculture sector. As such, given the steady growth of the corn sector nationwide since the early 2000s, the high poverty incidence of farmers engaged in this crop contradicts the high productivity being enjoyed by the corn industry as a whole.

The most widespread GM crop in the Philippines, corn production peaked at 7.77 million metric tons in 2014. According to the Philippine Grain and Feed Situation and Outlook 2017 (Corpuz, 2017), 70\% of all corn produced in the Philippines is of the yellow GMO variety and more than 70\% of total production in 2018 was intended for the livestock feed industry (IndexMundi, 2019), which supplies meat to more affluent households. High yield variety (HYV) corn include hybrid and genetically modified (GM) varieties; the former were introduced in the Philippines in the mid-1990s while the latter as early as 2002 (Ocampo \& Cotter, 2013). HYV corn varieties have seen a marked rise in cultivation since their introduction, with GMO varieties now comprising almost a third of the total corn produced in the country (Luces, 2014). Indeed, total corn production on a national level is at a surplus and continues to expand. It is apparent, therefore, that those who are gaining from this agricultural activity are not the smallholder farmers themselves. 
Research and innovations in agriculture have also grown over the last decades, significantly increasing productivity compared to what can be had from more conventional varieties and methods of cultivation. The possibilities are great in terms of feeding a burgeoning global population. In the Philippine countryside, however, as well as in many developing countries, there still exists a nagging question as to why there is a prevalence of poverty among predominantly smallholder agricultural households.

\section{TECHNOLOGICAL ADVANCES IN AGRICULTURE AND THE INFLUENCE OF GLOBAL MARKETS}

A form of corporate-driven agriculture built upon the use of the herbicide glyphosate, now the most widely utilized agri-chemical in the world, has emerged in recent decades (Main, 2016). A whole industry revolves around the use of this weed killer that modifies the genetic make-up of crops to be resistant to it and acquire traits from other organisms that give them the capacity to resist some common pests. Altering the genetic makeup of the plant at the cellular level, this process is called genetic modification and produces genetically modified organisms (GMOs). The results are "super crops" that need much less maintenance and inputs compared to their natural counterparts.

GMO technology, however, does not come cheap. The normal cost of planting one hectare of GMO corn ranges from $€ 550$ to $€ 585$ depending on the quality of the seeds used. This includes all necessary inputs and related costs for a successful harvest such as patented seeds, fertilizers, glyphosate, and labor for planting, applying fertilizers and glyphosate, and harvesting. The potential profit from a very successful harvest, however, coupled with a very good market price for corn, can be almost thrice the initial investment, enough to entice any farmer to invest in such a potentially profitable activity.

A poor farmer in the Philippines with access to only one to two hectares of land, however, will normally not be able to afford such a hefty investment despite such potentially high returns. To market the technology to the masses, traders and financers provide farmers with the needed capital to encourage their buy-in to the technology. The financing normally covers all inputs-seeds, glyphosate, and fertilizers-as well as labor costs in planting, spraying, harvesting, shelling, and drying. Farmers are also obliged to sell their crops directly to the financers. 
This has turned out to be a major success in that farmers are able to get loans easily for corn planting, although with interest rates ranging between 5\%-10\% per month covering between $20 \%-40 \%$, respectively, in a four-month cropping cycle. There are also numerous risks in upland farming such as unfavorable weather conditions, pest infestations, and the volatility of market prices. It is always the poor farmer who absorbs all of these losses in the end, incurring unpayable debts to their financers. Financers, moreover, also receive preferential treatment in the form of privileges and benefits, such as grace periods of up to three months for payments as well as bulk discounts, from the seed and chemical companies who supply the inputs, benefits which are not shared with the farmers.

Smallholder upland farmers in the Philippines generally have no legal tenure as well on the lands that they till as these lands officially belong to the state. There have been efforts from the 1990s into the 2000s that have focused on providing land security to upland dwellers; examples are the Indigenous Peoples through Certificate of Ancestral Domain Titles (CADT) and, to a lesser degree, Community Based Forest Management Agreements (CBFMA) which provided land agreements to individuals for up to 50 years. Yet even with such titles and smaller-scale agreements, the lack of government support and safeguards for communities has prevented any significant improvement in people's lives (Pulhin, Dizon, Cruz, Gevaña, \& Dahal, 2008).

\section{THE SOCIAL AND ENVIRONMENTAL COSTS OF TECHNOLOGICAL PROGRESS}

Corn farmers in the uplands of the Philippines have to deal with some of the most difficult conditions and circumstances in Philippine agriculture. First of all, the upland plains and rolling to hilly areas in which most corn is planted are marginal lands (Gerpacio et al., 2004). These areas have high erosion potential due to the precariousness of the landscape especially during extreme weather events such as excessive monsoon rains and typhoons, both of which are becoming more erratic with climate change. Farmers suffer a great deal in the wake of these weather events, including droughts that result in crop failures. Given that smallholder corn farmers normally seek financing for their crops, they are thrust into a cycle of debt that forces them to either lose the land that they till or let the financers use their plots until their debts are paid in full. To earn money to survive in the meantime, they work as laborers on their land paid for by the financers who have taken over. 
Communities of farmers in the past used to practice communal labor for land clearing, weeding, and harvesting wherein farmers helped one another in working each other's land in rotation during the cropping season (Upper Mapulo Community, 2018). This allowed for greater interaction among community members as they worked the land together. New farming practices associated with GMO corn cultivation, however, promote less labor in the planting process. The use of the herbicide glyphosate has eliminated the need for manual weeding as the chemical kills off all the undesirable plants upon contact. Agriculture has thus become an individualized undertaking as the use of herbicides in corn farming has eliminated the need for intensive labor. Current farming practices have commoditized labor in such a way that farm owners now need to hire people for very specific tasks such as planting, spraying of glyphosate during different phases of crop growth, and harvesting. In short, the new technology has transformed farming from traditional subsistence agriculture into a cash-based endeavor for smallholder corn farmers.

The agricultural practices that have emerged in the recent decades have thus fragmented upland farming communities in the Philippines by reducing occasions of interaction and relations among themselves through communal agricultural activities. Yet according to Pope Francis, "human life is grounded in three fundamental and closely intertwined relationships: with God, with our neighbour and with the earth itself" (Francis, 2015: \#66), and when we break one of these relationships, we break the others as well (Turkson, 2015).

Peter Cardinal Turkson, president of the Pontifical Council for Justice and Peace, said it best in his article "Laudato Si and the Vocation to Agriculture":

\footnotetext{
Advanced technologies also receive attention in the encyclical. Technology is not all bad. The technical ability to increase crop yields has done wonders for health and nutrition - think of the "green revolution". But Pope Francis is making the point that technology unmoored from morality can lead to domination over people and the earth, especially when technology is in the hands of people with great resources. What results is a technocratic paradigm that tends to dominate economics and political life. (Turkson, 2015)
}

The corporate pursuit of profits that utilizes technology at the expense of the environment severely damages the critical balance needed for a sustainable relationship with the land. "Where profits alone count, there can be no thinking about the rhythms of nature, its phases of decay and regeneration, or the complexity of ecosystems which may be gravely upset by human intervention... Whatever is 
fragile, like the environment, is defenceless before the interests of a deified market, which become the only rule" (Francis, 2015: \#190, \#56). Contributing to this, moreover, is a forced dependence of farmers on corporation-generated inputs that not only cost money but also circumvent natural processes and impoverish the land and its natural ability to regenerate. Such a focus on short-term gains exploits farmers who become victims of an oppressive system that puts great pressure on them to produce yet with a lopsided distribution of gains and virtually no protection from natural and anthropogenic risks. The result is that almost all smallholder farmers in the Philippine uplands dream of a better life for their children, which is anything but the burdens they have associated in their own lives with toiling over the land (Nalumusan Community, 2018).

\section{A PATH TO SUSTAINABILITY-TOWARD RESPECTFUL AND CARING RELATIONSHIPS WITH THE LAND AND ITS PEOPLE}

Given that the economic concept of maximizing utility has taken over how we live our lives, the systemic and coordinated oppression created by society in the uplands of the Philippines (and throughout the world) has evolved to be quite complex. It has prevented us from drawing the line between what is enough and what is too much. In fact, the maximization of profit has led to abuses not only in terms of human dignity and the rights of smallholder farmers but also in terms of the land itself. At a time when a third of all the food produced globally goes to waste while one in every ten persons is hungry (Fan, 2017), that there is not enough to feed the world is clearly not the problem. Indeed, while distribution is one of the main causes of this shameful reality, a critical factor in all of this is society's insatiable consumption.

Believing in the fallacy that the world has an infinite supply of resources has brought us to this point in human history where we are faced with a stark realitythat a major shift is needed in how we view our relationships with one another and with the land. We have fragmented our way of life in such a profound way that we have isolated ourselves from the very essence of our being. The excessive focus on the self, brought about by consumerist culture, has prevented us from taking part in caring relationships that are at the core of our existence. We have forgotten our connectivity to the earth and to the lives of those who struggle like us to live a decent life. 
As we become more fragmented and degraded as a society, so does the land and its integrity. The water that sustains all life, for example, hangs precariously in the balance as we continue exploiting the land for greater economic gain, resulting in a downward spiral that deteriorates the land and the associated water resources that flow through it.

Such a cycle of degradation needs to be broken by employing both mid- and long-term solutions. Efforts that seek to address the problems using a multi-faceted yet integrated approach have thus been put in place, especially given that forestbased indigenous cultures are key to sustainable management. Livelihoods need to be given focus immediately as they are the more important and urgent concern; current livelihood options that have evolved through global market forces and infringed on the local setting have contributed greatly to the worsening situation of the uplands and its communities. The youth, in particular, are most affected in that the current context gives them extremely limited options that only reinforce both the exploitation of smallholder corn farmers and the further disintegration of the land.

Culture-based education grounded on traditional forest resource management practices is a long-term solution for rebuilding and strengthening the protection, management, and regeneration of remaining forests which are crucial in regulating and ensuring the sustainability of water resources in Mindanao. This is done formally through the Apu Palamguwan Cultural Education Center (APC) which is officially recognized by the Philippine government as an Indigenous People's school. The education program there is centered on the gaup or ancestral domain, where the indigenous communities are recognized by the state as having tenure and rights over the land and its resources. Culture-based forest management as such has been consolidated and put in place as formal subjects in the school.

Alternative forms of livelihood that allow the soil and its resources to regenerate, such as bamboo production, treatment, and processing, are also being currently explored. Bamboo opens up huge potentials for low-cost building materials that offer alternatives to wood and can be harvested regularly from the clumps. Organic agriculture, which addresses food security down to the household level, is also being developed as an integral subject in the school. The EcoAgri program in APC, for instance, seeks to cultivate non-commercial agriculture that does not rely heavily 
on chemical inputs and patented seeds. Such programs are not limited to the formal school setup; they are also made available as short-term, vocational-technical courses that offer government certification when available.

At the very core of all these programs is a culturally-sensitive leadership formation that helps the indigenous youth understand both the changing context of broader society and the importance of facing these challenges while keeping their cultural traditions and relations alive. As bleak as our current situation may seem, there is always a way forward. We are now being called to rediscover our humanity by simply being mindful of our needs, the needs of others, and the needs of the land-to be mindful of what is enough for us to live a full life. There is hope in such a simple yet fundamental change in how we live our lives, and it is this hope that can move us to heal the wounds that we have inflicted on our society and the damage that we have done to our common home.

\section{REFERENCES}

Cardenas, D. 2008. Philippine agriculture: Status, trends, \& challenges. Philippine Council for Agriculture, Aquatic, and Natural Resources Research and Development.

Corpuz, P. 2017. Philippine grain and feed situation and outlook. GAIN Report, No. RP 1702. Washington, DC: USDA Foreign Agricultural Service. Available at https:/gain.fas.usda.gov/Recent\%20GAIN\%20Publications/Grain\%20and\%20 Feed\%20Annual_Manila_Philippines_3-17-2017.pdf.

Espiritu, N. O., Casin, C. S., \& Camacho, S. C. 2010. Development pathways in the Philippine uplands: Impacts and influences on forest resource management and human well-being. Asian Journal of Agriculture and Development, 7(2): 27-47.

Fan, S. 2017. Reducing food loss is key to end hunger and undernutrition by 2025. International Food Policy Research Institute. Available at http://www.ifpri.org/ blog/reducing-food-loss-key-end-hunger-and-undernutrition-2025.

FAO [Food and Agriculture Organization of the United Nations]. 2018. The state of food and agriculture: Migration, agriculture and rural development. Rome. Available at http://www.fao.org/3/I9549EN/i9549en.pdf. 
Francis. 2015. Laudato si': On care for our common home. Rome: Libreria Editrice Vaticana. Available at http://w2.vatican.va/content/francesco/en/encyclicals/ documents/papa-francesco_20150524_enciclica-laudato-si.html.

Gerpacio, R. V., Labios, J., Labios, R., \& Diangkinay, E. 2004. Maize in the Philippines: Production systems, constraints, and research priorities. Mexico: D. F. / CIMMYT.

Harvey, F. 2018. Invest in farming to stop youth migrating to cities, urges UN. The Guardian, October 15. Available at https://www.theguardian.com/world/2018/ oct/15/invest-in-farming-to-stop-youth-migrating-to-cities-urges-un.

IndexMundi. 2019. Philippines corn feed domestic consumption by year (1000 MT). IndexMundi.com Available at https://www.indexmundi.com/agriculture/?coun try=ph\&commodity=corn\&graph=feed-domestic-consumption.

Lowder, S. K., Skoet, J., \& Singh, S. 2014. What do we really know about the number and distribution of farms and family farms worldwide? Background paper for The State of Food and Agriculture 2014. ESA Working Paper No. 14-02. Rome: FAO.

Luces, K. 2014. Genetically-modified crops, fastest adopted technology in recent history-study. GMA News Online, March 8. Available at http://www. gmanetwork.com/news/story/351702/scitech/science/genetically-modifiedcrops-fastest-adopted-technology-in-recent-history-study.

Main, D. 2016. Glyphosate now the most-used agricultural chemical ever. Newsweek, February 2. Available at http://www.newsweek.com/glyphosate-now-most-usedagricultural-chemical-ever-422419.

Nalumusan Community. 2018. Farmer community focus group discussion in Sitio Nalumusan, Barangay Silae, Malaybalay City, Bukidnon, Philippines.

Ocampo, D., \& Cotter, J. 2013. White corn in the Philippines: Contaminated with genetically modified corn varieties. GreenPeace.

Padilla, L. D. 2011. CORN: Optimizing productivity and competency. $\boldsymbol{B} \boldsymbol{A} \boldsymbol{R}$ Research and Development Digest, 13(4). Available at https://web.archive.org/ 
web/20131116225701/http://www.bar.gov.ph/digest-home/digest-archives/3642011-4th-quarter/2045-corn-optimizing-productivity-and-competency.

President of the Philippines. 1975. Revising presidential decree no. 389, otherwise known as the Forestry Reform Code of the Philippines. Available at https:// www.officialgazette.gov.ph/1975/05/19/presidential-decree-no-705-s-1975/.

PSA [Philippine Statistics Authority]. 2009. Major crops statistics of the Philippines 2003-2008_regional and provincial. Quezon City, Philippines: Philippine Statistics Authority. Available at https://psa.gov.ph/sites/default/files/major_ crops_stat2003-2008.pdf.

PSA. 2014. Major crops statistics of the Philippines, 2009-2013. Quezon City, Philippines: Philippine Statistics Authority. Available at https://psa.gov.ph/sites/ default/files/MajorCrops09-13.pdf.

PSA. 2015. Special report-highlights of the 2012 census of agriculture (2012 CA). Quezon City, Philippines: Philippine Statistics Authority. Available at https:// psa.gov.ph/content/special-report-highlights-2012-census-agriculture-2012-ca.

Pulhin, J., Dizon, J., Cruz, R. V., Gevaña, D., \& Dahal, G. 2008. Tenure reform on Philippine forest lands: Assessment of socio-economic and environmental impacts. Laguna, Philippines: College of Forestry and Natural Resources, University of the Philippines Los Baños (UPLB).

Rapsomanikis, G. 2015. The economic lives of smallholder farmers: An analysis based on household data from nine countries. Rome: Food and Agriculture Organization of the United Nations.

Reyes, C., Tabuga, A., Asis, R., \& Datu, M. B. 2012. Poverty and agriculture in the Philippines: Trends in income poverty and distribution. Discussion Paper Series No. 2012-09. Quezon City: Philippine Institute for Development Studies. Available at http://dirp3.pids.gov.ph/ris/dps/pidsdps1209.pdf.

Robinson, J. 2015. The 20 fastest-growing economies this year. Bloomberg-Markets, February 26. Available at http://www.bloomberg.com/news/articles/2015-02-25/ the-20-fastest-growing-economies-this-year. 
Turkson, P. K. A. 2015. Laudato Si and the vocation to agriculture: A prince of the Church explains the connection. Catholic Rural Life, Summer. Available at https://s3.amazonaws.com/catholicrurallife/wp-content/ uploads/20150827184825/10-13.pdf.

Upper Mapulo Community. 2018. Farmer community focus group discussion in Sitio Upper Mapulo, Barangay Mapulo, Malaybalay City, Bukidnon, Philippines.

Walpole, P. 2010. Figuring the forest figures: Understanding forest cover data in the Philippines and where we might be proceeding. Quezon City, Philippines: Environmental Science for Social Change. Available at http://download.essc.org. ph/forest/ESSC-PWalpole_Figuring\%20forest\%20figures_reduced_.pdf.

World Bank. 2018. Urban population (\% of total population). United Nations Population Division. Available at https://data.worldbank.org/indicator/SP.URB. TOTL.IN.ZS.

Acknowledgements. The author wishes to acknowledge the contributions of his colleagues at the ESSC in this research endeavor. He also acknowledges the contributions of ESSC's partners in its continuing work, particularly its Belgian counterparts in the LUCID project.

J. Andres F. Ignacio has been interested in environmental work since he finished his bachelor's degree in Interdisciplinary Studies from the Ateneo de Manila University. He obtained an MSc degree in Water Resources Management from the University of Wisconsin-Madison in the early 1990s and received a diplôme d'études approfondies in Agronomy and Bioengineering (major in geomatics and remote sensing) from the Université Catholique de Louvain in 2001. He then obtained his doctorate degree in Geography from the University of Namur in 2015. His interests revolve around the convergence and interplay between human and physical systems and the challenges that ensue in relation to their management. His work is oriented toward the promotion of greater human security and he values community-based processes, believing that these are the key to effective and responsive management. He is currently serving as the Director for Planning and as the Geomatics Manager of ESSC and is based in Mindanao. 
The Institute of Environmental Science for Social Change (ESSC) is a Jesuit research and training institute that promotes environmental sustainability and social justice through the integration of scientific methodologies and social processes. It networks across the Asia Pacific region in moving an agenda of science for sustainability, and aims to contribute toward building scientific capacity that engenders people's commitment and integrity to see positive changes emerge and develop and enables a discernment of our life in the world with a deeper human spirit. 